\title{
Dielectric Resonator Reflectarray Antenna Unit Cells for 5G Applications
}

\author{
Nur Fazreen Sallehuddin", Mohd Haizal Jamaluddin², Muhammad Ramlee Kamarudin ${ }^{3}$, \\ Muhammad Hashim Dahri ${ }^{4}$, Siti Umairah Tajol Anuar ${ }^{5}$ \\ ${ }^{1,2,4,5}$ Wireless Communication Centre, Universiti Teknologi Malaysia, Johor, Malaysia \\ ${ }^{3}$ Centre for Electronic Warfare, Information and Cyber, Cranfield University, UK
}

\begin{tabular}{l} 
Article Info \\
\hline Article history: \\
Received Jan 27, 2018 \\
Revised May 30, 2018 \\
Accepted Jun 8, 2018 \\
\hline Keyword: \\
Cross microstrip patch \\
DRA reflectarray \\
Phase range \\
Reflection loss \\
Unit cell
\end{tabular}

\begin{abstract}
This paper presents an investigation for the performance comparison of three different unit cell configurations operating at $26 \mathrm{GHz}$ for $5 \mathrm{G}$ applications. The unit cells are cross shape dielectric resonator, cross microstrip patch and cross hybrid dielectric resonator. Verification of the comparison has been done by simulations using commercial Computer Simulation Technology Microwave Studio (CST MWS). The simulated results for reflection phase, slope variation, reflection loss and $10 \%$ bandwidth were analyzed and compared. The results indicate that the optimum configuration to be deployed for the reflectarray's unit element in order to fulfill the $5 \mathrm{G}$ requirements of a wide bandwidth is the cross hybrid DRA. This configuration is a combination of cross DRA with cross microstrip patch as the parasitic element in order to tune the phase and provide a wide phase range with smooth variation slope. Cross hybrid DRA provided a wide phase range of $520^{\circ}$ with $0.77 \mathrm{~dB}$ loss and $10 \%$ bandwidth of $160 \mathrm{MHz}$.
\end{abstract}

Copyright @ 2018 Institute of Advanced Engineering and Science. All rights reserved.

\section{Corresponding Author:}

Nur Fazreen Sallehuddin, Wireless Communication Centre, Universiti Teknologi Malaysia, 81310 Johor Bahru, Johor, Malaysia. Email: nfazreen7@live.utm.my

\section{INTRODUCTION}

Wireless communication systems have been growing rapidly evolving from first generation (1G) to fifth generation (5G). It is widely agreed that compare to fourth generation $(4 \mathrm{G})$ network, the $5 \mathrm{G}$ network should achieve 1000 times the system capacity, 10 times the spectral efficiency and energy efficiency [1]. The fourth generation (4G) wireless communication systems have been deployed in many countries, and now 4G technology is reaching maturity [2]. Therefore, the wireless system designers and the researchers have started research on the $5 \mathrm{G}$ wireless system that will provide very high speeds and efficient use of available bandwidth with frequency spectrum from $3 \mathrm{GHz}$ to $300 \mathrm{GHz}$. Wide bandwidth is the most effective and straightforward method to provide the foreseen data demands for $5 \mathrm{G}$ services expected to be commercially available in 2020 and beyond [3]. In conjunction with 5G systems, the most important components that have to be taken into account in order to use a reflectarray antenna for high data rate application is its bandwidth and gain [2].

Reflectarray antennas combine some of the best features and positive characteristic of reflector and phased arrays antenna [4], [5]. It consists of an array of elementary antenna excited by a feed as shown in Figure 1. The feed is positioned at the focal distance of the array and normally measured in $f / \mathrm{D}$ ratio where $f$ is the distance between the feed and the reflectarray whereas D is the maximum length of the reflectarray [6]-[8]. As no feeding network is required in reflectarray, losses can be reduced. This antenna is able to reradiate and scatter the incident waves coming from the feed with electrical phases that are required to form 
a planar phase front in the far-field distance into the desired direction. One of the essential parts of the reflectarray is to design the precise characterization of the unit elements by depends on the unit element's geometry to predict the phase-shift accurately. An important aspect of reflectarray analysis which are the radiation patterns only can be evaluated once the unit element has been fully characterize and the full reflectarray antenna is designed [9].

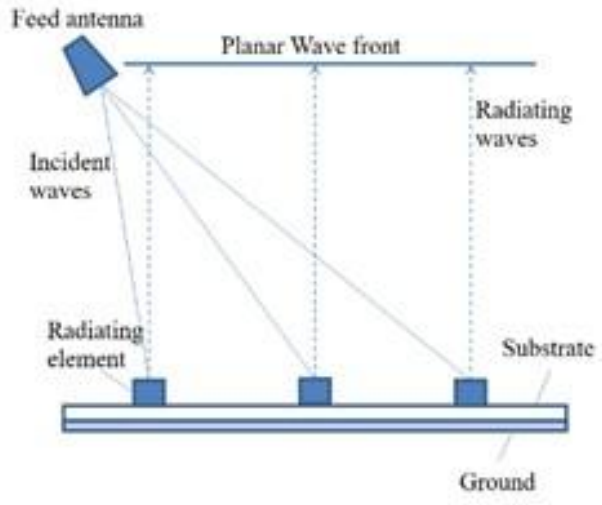

Figure 1. Reflectarray antenna working principle

In the early development of reflectarray antenna, researchers contributed to develop a unit element for reflectarrays by using microstrip due to their advantages such as easy deployment in space, reducing cost production, low profile, low weight, flatness and beam steering capability. However, the efficiency of the microstrip at millimeter wave frequencies may drop significantly and the conductor loss becomes severe. As a solution, dielectric resonator antenna (DRA) reflectarray with low loss and high phase range was proposed [10], [11].

Dielectric resonator (DR) have been widely used as antenna element started in early nineteeneighties, in which the DR is made of high dielectric constant material that are known as high Q-factor elements [12]. Besides as energy storage devices, dielectric resonators can be efficient radiators [13]. DRA has been explored for designing various reflectarray antennas to achieve large reflection phase range, as well as low reflection loss. One common approach to introduce phase shifts to the radiating elements is by varying one of its geometrical parameters such as the length of the DRA. Such change will be converted into a reflection phase variation. However, DRAs with different sizes makes the fabrication process complex. Therefore, DRA reflectarray unit element can also be incorporated with various microstrip elements such as slots, patches and strip for designing broadband reflectarray [14]. Moreover, multi-resonants elements on a single dielectric layer have been suggested in these recent years to improve bandwidth and at the same time keep the simple fabrication process. Among them are coplanar parallel dipoles, concentric squared, a combination of square patch and square ring slots and cross shape rings [15]. As a result, it is possible to produce reflection phase range that more than $360^{\circ}$, while achieving smooth variation slope. Another approach that has a possibility to improve the bandwidth by attaining high phase range for the reflectarray's element is dual-polarized technique [16]. The selection of the polarization can be achieved by using rectangular shapes for linear polarization and square shapes, circular shapes or crossed shapes for dual or circular polarization [12], [17].

Motivated by the above previous researches on the unit cells, the purpose of this paper is to investigate the performance of several different unit cell configurations in terms of the reflection characteristics and phase range that will be the basic building block of the reflectarray in $5 \mathrm{G}$ applications at operating frequency of $26 \mathrm{GHz}$. The specifications and criteria are focus on achieving wide phase range which highly related to the large bandwidth of operation and low reflection loss. The goal is to determine the best candidate to be deployed for the reflectarray's unit element for the DRA-based reflectarray for 5G applications in term of wide bandwidth, low reflection loss and easy fabrication.

\section{RESEARCH METHOD}

The unit cells of the reflectarray proposed in this paper for the investigation consist of DRA with dielectric constant, $\varepsilon_{\mathrm{r}}=10$. For the cross shape DRA (CDRA) incorporate of two same sizes of rectangular 
DRA (RDRA) and the cross microstrip patch incorporate of two same sizes of the rectangular patch. The resonant frequencies, $f_{0}$ for the RDRA can be predicted by using equation derived from the Dielectric Waveguide Model [12].

$$
k_{z} \tan \left(\frac{k_{z} h}{2}\right)=\sqrt{\left(\varepsilon_{r}-1\right) k_{0}^{2}-k_{Z}^{2}}
$$

Where $\mathrm{k}_{z}$ is the wave propagation number in the $z$-direction, $h$ is the width in the $z$-direction and $\mathrm{k}_{0}$ is the free space wave number. All types of the unit cell have been designed and simulated by using the commercially Computer Simulation Technology Microwave Studio (CST MWS) software to analyze the results and obtain the optimum parameter value. The dielectric substrate that used in these designs is Duroid 5880 with a thickness $0.381 \mathrm{~mm}$, a permittivity of 2.2 with a loss tangent of 0.0009 . Several different frequency bands for communication $5 \mathrm{G}$ have been suggested by their ability to achieve the required properties and features [18]. In this work, the resonant frequency of $26 \mathrm{GHz}$ has been selected from the frequency band of $24.25 \mathrm{GHz}$ to $27.5 \mathrm{GHz}$ for design considerations. The unit cell elements are simulated using waveguide setup with periodic boundary condition with the E-wall (top and bottom surfaces) and Hwall (left and right sides) to support an incident plane as depicting in Figure 2 for infinite array approach. The incident wave is position at the top surface of the waveguide and the unit element is placed at the bottom surface of the waveguide. In the next subsection, the designs of several different unit cells are presented.

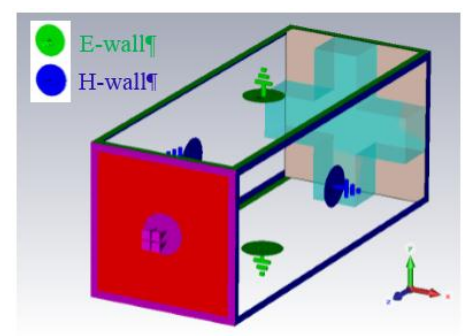

Figure 2. Waveguide simulation setup for the unit cell

\subsection{Rectangular DRA}

Figure 3 shows the design configuration of the rectangular DRA. The design parameters after simulation and optimization are shown in Table 1. The width of DRA, W is fixed at $2.4 \mathrm{~mm}$ while the length of DRA, $\mathrm{L}$ is varying from $4.5 \mathrm{~mm}$ to $8.0 \mathrm{~mm}$.

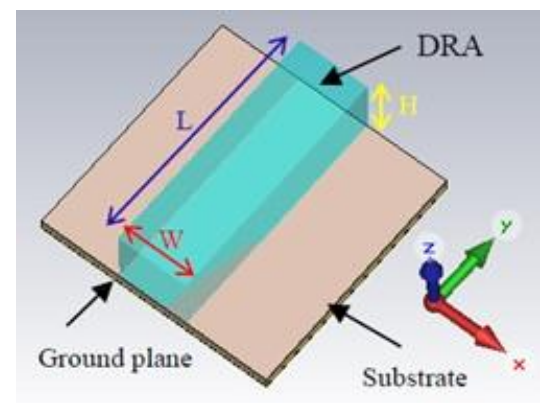

(a) $3 \mathrm{D}$ view

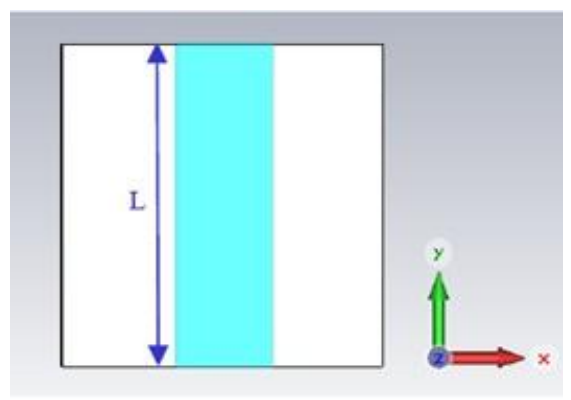

(b) Top view

Figure 3. Rectangular DRA unit cell

Table 1. Rectangular DRA Unit Cell Design Parameters

\begin{tabular}{cc}
\hline Parameter & Value $(\mathrm{mm})$ \\
\hline $\mathrm{L}$ & Varies from 4.5 to 8.0 \\
$\mathrm{~W}$ & 2.4 \\
$\mathrm{H}$ & 2.2 \\
\hline
\end{tabular}




\subsection{Cross shape DRA}

The design configuration of the cross shape DRA that have been combined from the two rectangular DRA dimension is shown in Figure 4. Table 2 shows the optimized design parameters of the cross DRA. The width of DRA, W is fixed at $2.4 \mathrm{~mm}$ while the length of DRA, L is varying from $4.5 \mathrm{~mm}$ to $8.0 \mathrm{~mm}$ (to compare with rectangular DRA) and varying from $1.5 \mathrm{~mm}$ to $8.0 \mathrm{~mm}$ for the next section (to compare with other cross shape unit cells).

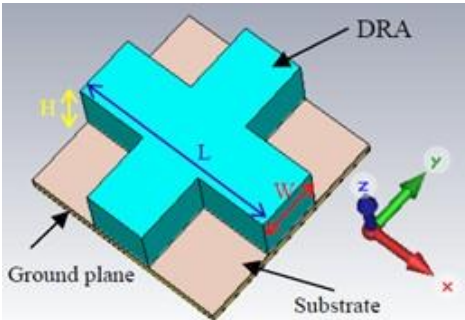

(a) 3D view

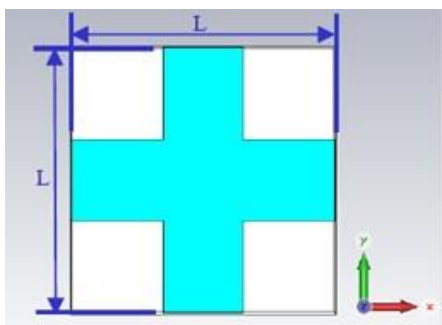

(b) Top view

Figure 4. Cross shape DRA unit cell

Table 2. Cross DRA Unit Cell Design Parameters

\begin{tabular}{cc}
\hline Parameter & Value $(\mathrm{mm})$ \\
\hline $\mathrm{L}$ & Varies from 1.5 to 8.0 \\
$\mathrm{~W}$ & 2.4 \\
$\mathrm{H}$ & 2.2
\end{tabular}

\subsection{Cross microstrip patch}

The dimension of the microstrip patch with operating frequency of $26 \mathrm{GHz}$ was determined by a series of a mathematical equation. Then the two same sizes of the rectangular microstrip patch are designed in cross shape. This unit cell design using cross microstrip patch as the phase variation technique. The configuration of the unit cell is shown in Figure 5 and Table 3 shows the optimum parameters obtained. The width of microstrip, $\mathrm{W}_{\mathrm{P}}$ is fixed at $1.5 \mathrm{~mm}$ while the length of microstrip, $\mathrm{L}_{\mathrm{P}}$ is varying from $1.5 \mathrm{~mm}$ to $8.0 \mathrm{~mm}$.

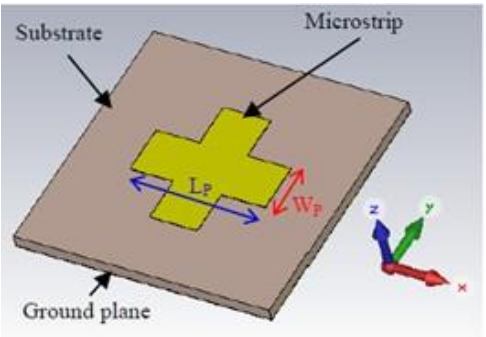

(a) 3D view

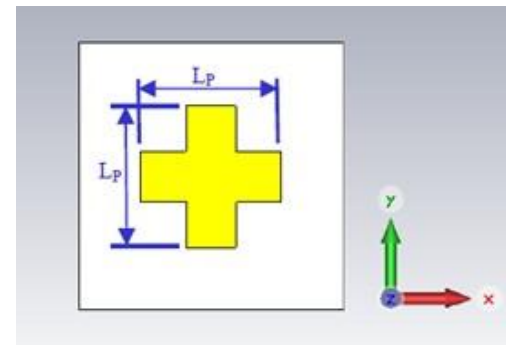

(b) Top view

Figure 5. Cross microstrip unit cell

Table 3. Cross Microstrip Cell Design Parameters

\begin{tabular}{cc}
\hline Parameter & Value $(\mathrm{mm})$ \\
\hline $\mathrm{L}_{\mathrm{P}}$ & Varies from 1.5 to 8.0 \\
$\mathrm{~W}_{\mathrm{P}}$ & 1.5 \\
\hline
\end{tabular}




\subsection{Cross hybrid DRA}

The configuration of the cross hybrid DRA is shown in Figure 6. Table 4 shows the unit cell design parameters after simulation and optimization. This unit cell consists of a cross shape DRA combined with cross shape microstrip patch below the cross DRA whereas the cross microstrip patch as the parasitic element to tune the phase of the unit cell. Designing DRA with different size is always difficult to be implemented [10]. Therefore, a design with fixed cross DRA size with the cross microstrip patch as the parasitic element to tune the phase response by varying its length is designed. The width of DRA, W is fixed at $2.4 \mathrm{~mm}$ while the length of DRA, L is fixed at $8.0 \mathrm{~mm}$. On top of that, the width of microstrip, $\mathrm{W}_{\mathrm{P}}$ is fixed at $1.5 \mathrm{~mm}$ while the length of microstrip, $\mathrm{L}_{\mathrm{P}}$ is varying from $1.5 \mathrm{~mm}$ to $8.0 \mathrm{~mm}$.

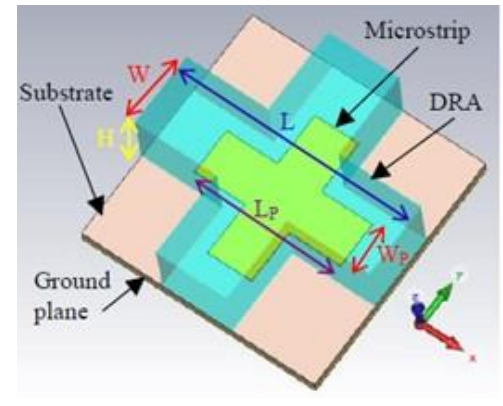

(a) 3D view

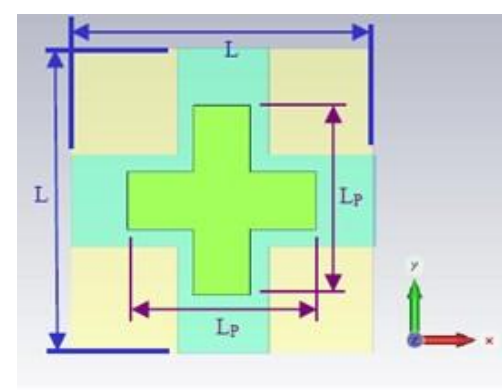

(b) Top view

Figure 6. Cross hybrid DRA unit cell

Table 4. Cross Hybrid DRA Unit Cell Design Parameters

\begin{tabular}{cc}
\hline Parameter & Value $(\mathrm{mm})$ \\
\hline $\mathrm{L}$ & 8.0 \\
$\mathrm{~W}$ & 2.4 \\
$\mathrm{H}$ & 2.2 \\
$\mathrm{~L}_{\mathrm{P}}$ & Varies from 1.5 to 8.0 \\
$\mathrm{~W}_{\mathrm{P}}$ & 1.5 \\
\hline
\end{tabular}

\section{RESULTS AND ANALYSIS}

The selected designs have been analyzed numerically by using CST MWS simulation tools. In this section, the results for several types of the unit cell for the reflectarray's unit cell are discussed in terms of reflection phase range, reflection loss and $10 \%$ bandwidth.

\subsection{Comparison of the simulated results between rectangular DRA and cross shape DRA}

The two main parameters to show the performance of the reflectarray's unit cells are the reflection phase and the reflection loss. An important parameter that is availed to analyze the reflectivity and bandwidth of reflectarray is reflection phase [19]. Figure 7 shows the reflection phase of $S_{11}$ for rectangular DRA (RDRA) and cross DRA. The graphs clearly indicate that cross DRA provides wider phase range than rectangular DRA. This is because the cross DRA unit cell with two resonants element provide a dualpolarization technique that could effectively attain higher phase range than rectangular DRA. The phase range and slope variation of both types unit cells are summarized in Table 5. Based on the result, the slope variation of both unit cells are smooth which indicate that DRA-based unit cells can provide wide bandwidth. Therefore, the cross DRA is selected to combine with microstrip for further study on hybrid unit cell.

Table 5. Phase Range and Slope Variation for different Configuration of DRA Unit Cells at $26 \mathrm{GHz}$

\begin{tabular}{lcl}
\hline Type of Unit Cell & $\begin{array}{c}\text { Phase range } \\
\text { (degrees) }\end{array}$ & Slope \\
\hline Rectangular DRA & $332^{\circ}$ & Slow \\
Cross DRA & $497^{\circ}$ & Slow \\
\hline
\end{tabular}




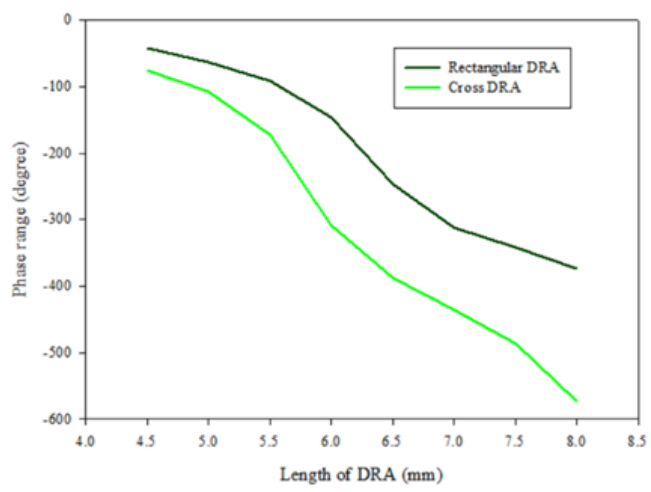

Figure 7. Phase of $S_{11}$ for rectangular DRA and cross DRA unit cells

\subsection{Comparison of the simulated results for three different cross-shape unit cell configurations for bandwidth enhancement}

The reflection phase of $S_{11}$ for three different cross shape configurations obtained by varying the length of the tunable parameter is presented in Figure 8. Based on the results, it can be seen that the cross DRA unit cell exhibit highest reflected phase range which is $684^{\circ}$, followed by cross hybrid DRA phase range equal to $520^{\circ}$ and cross microstrip patch phase range is $298^{\circ}$. Limited reflection phase range that less than 360 degrees causes phase errors and consequently reduces its directivity that will deteriorate the antenna performance [9].

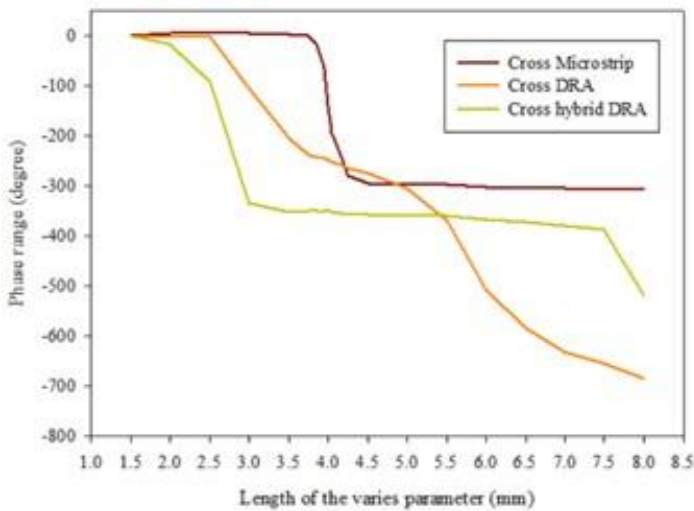

Figure 8. Phase of $\mathrm{S}_{11}$ for different unit cells

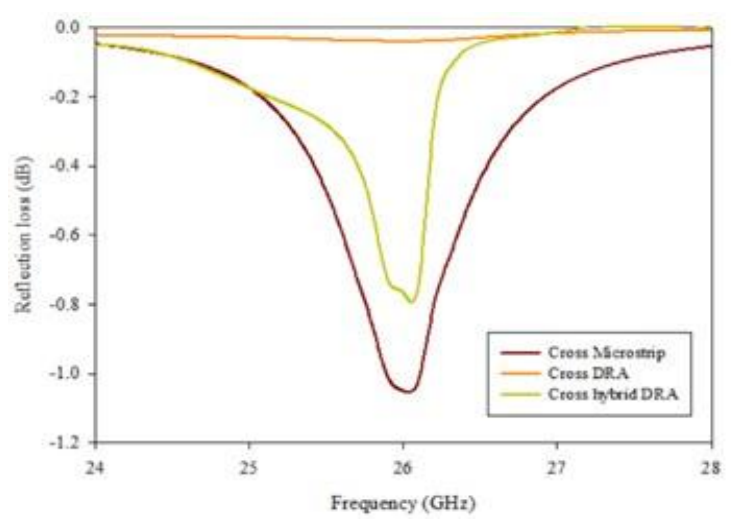

Figure 9. Reflection loss curves for different unit cells

For cross microstrip patch case, the gradient slope of the phase variation versus variable length is steeper than the other two unit cells. This is expected to result in a reduced bandwidth [20]. Table 6 shows the phase range and gradient slope for the structures that have been analyzed as the possible candidate for the design of DRA-based reflectarray. In terms of gradient variation, the slope of cross DRA and cross hybrid DRA unit cell is smoother than the slope of cross microstrip patch. The more gradual gradient variation of the reflection phase curve corresponds to the wider bandwidth of the unit element [20], [21]. The phase range of the cross DRA is wider than cross hybrid DRA, but in term of fabrication matter, the cross hybrid DRA with fixed DRA is a better option than cross DRA to decrease the fabrication complexity during an array arrangement.

Reflection loss or also known as insertion loss in reflectarray is another vital parameter in the analysis of reflectarray. Normally a reflectarray antenna always exhibits some losses. Therefore, the reflection coefficient or reflection loss is measured less than $1 \mathrm{~dB}$ for a reflectarray and the lower loss is the better. Figure 9 illustrates the reflection loss for the three different unit cell configurations. It is demonstrated in Figure 9 that cross DRA is observed to provide the lowest insertion loss value of $0.04 \mathrm{~dB}$ whereas the cross hybrid DRA gives $0.77 \mathrm{~dB}$ insertion loss. Whilst the cross microstrip unit cell with $1.05 \mathrm{~dB}$ gives the 
highest insertion loss value. This is due to the dielectric resonator element gives low loss as compared to microstrip element that gives higher conductor loss which produced by the microstrip patch.

The bandwidth of the unit cell of the reflectarray can be calculated by the reflection loss curves. The bandwidth is determined by moving $10 \%$ above the maximum reflection loss value [22]. The $10 \%$ bandwidth of the three unit cell configurations are shown in Table 7. From Table 7, it shows that the cross hybrid DRA unit cell offers the wider bandwidth of $160 \mathrm{MHz}$ whereas the cross microstrip unit cell gives a minimum bandwidth of $136 \mathrm{MHz}$. The results indicate that the cross DRA unit cell gives the lowest reflection loss with broader bandwidth due to the absence of conductor's losses and surface wave losses.

Table 6. Phase Range and Slope Variation for different Configuration of Unit Cells at $26 \mathrm{GHz}$

\begin{tabular}{lcc}
\hline Type of Unit Cell & $\begin{array}{c}\text { Phase range } \\
\text { (degrees) }\end{array}$ & Slope \\
\hline Cross Microstrip & $298^{\circ}$ & Fast \\
Cross DRA & $684^{\circ}$ & Slow \\
Cross hybrid DRA & $520^{\circ}$ & Slow \\
\hline
\end{tabular}

Table 7. Reflection Loss and 10\% Bandwidth for different Unit Cells at $26 \mathrm{GHz}$

\begin{tabular}{lcc}
\hline \multicolumn{1}{c}{ Type of Unit Cell } & $\begin{array}{c}\text { Reflection Loss } \\
(\mathrm{dB})\end{array}$ & $\begin{array}{c}10 \% \text { Bandwidth } \\
(\mathrm{MHz})\end{array}$ \\
\hline Cross Microstrip & 1.05 & 136 \\
Cross DRA & 0.04 & 1617 \\
Cross hybrid DRA & 0.77 & 160 \\
\hline
\end{tabular}

\section{CONCLUSION}

The design configurations with three potential cross shape unit cell designs for the reflectarray unit cell at $26 \mathrm{GHz}$ were investigated for the performance optimization of the reflectarray. The CST MWS simulation showed that the best candidate to be deployed for the reflectarray's unit element in order to fulfill the $5 \mathrm{G}$ requirements of a wide bandwidth is the cross hybrid DRA which is the combined fixed cross DRA with cross microstrip patch as the parasitic element. The parasitic element used to tune the phase to give a wide phase range with smooth variation slope. Besides, it is shown that the cross hybrid DRA unit cell gives low reflection loss with better bandwidth performance. Easy implementation and fabrication also emphasized in a selection of the unit element. The simulation results for the unit cells will be validated experimentally in next stage. The design for full reflectarray to predict the overall DRA reflectarray antenna performance and further investigation into how a higher gain can be achieved are being conducted by the authors.

\section{ACKNOWLEDGEMENTS}

The authors would like to thank the Ministry of Education (MOE) for sponsoring the PhD study at Universiti Teknologi Malaysia. Also, special thanks go to UTM GUP (votes 4J220, 05H62, 13H26, 03G59 and 4F733) and Ministry of Science Technology and Innovation (MOSTI) (vote 4S134) for sponsoring this work.

\section{REFERENCES}

[1] C.-X. Wang, F. Haider, X. Gao, X.-H. You, Y. Yang, D. Yuan, H. Aggoune, H. Haas, S. Fletcher, and E. Hepsaydir, "Cellular architecture and key technologies for 5G wireless communication networks," IEEE Commun. Mag., vol. 52, no. 2, pp. 122-130, 2014.

[2] J. G. Andrews, S. Buzzi, W. Choi, S. V. Hanly, A. Lozano, A. C. K. Soong, and J. C. Zhang, "What will 5G be?," IEEE J. Sel. Areas Commun., vol. 32, no. 6, pp. 1065-1082, 2014.

[3] Z. Pi and F. Khan, "An introduction to millimeter-wave mobile broadband systems," IEEE Commun. Mag., vol. 49, no. 6, pp. 101-107, 2011.

[4] S. Mener, R. Gillard, R. Sauleau, C. Cheymol, and P. Potier, "Design and Characterization of a CPSS-Based UnitCell for Circularly Polarized Re fl ectarray Applications," IEEE Trans. Antennas Propag., vol. 61, no. 4, pp. 2313-2318, 2013.

[5] M. F. M. Yusoff, R. Sauleau, Z. Johari, M. K. A. Rahim, and H. A. Majid, "A Novel Right Handed Circular Polarization Folded Reflectarray Antenna at 60 GHz," Int. J. Electr. Comput. Eng., vol. 7, no. 3, p. 1580, 2017.

[6] M. M. Tahseen and A. A. Kishk, "Broadband Performance of Novel Closely Spaced Elements in Designing KaBand Circularly Polarized Reflectarray Antennas,” vol. 1225, no. c, pp. 1-4, 2016.

[7] M. H. Dahri, M. R. Kamarudin, M. H. Jamaluddin, M. Inam, and R. Selvaraju, "Broadband Resonant Elements for 5G Reflectarray Antenna Design,”vol. 15, no. 2, pp. 793-798, 2017. 
[8] M. H. Dahri, M. R. Kamarudin, M. H. Jamaluddin, and R. R. Selvaraju, "Performance Investigation of Reflectarray Resonant Elements for 5G Communications," IEEE Asia-Pacific Conf. Appl. Electromagn., no. December, pp. 11-13, 2016.

[9] J. Huang and J. A. Encinar, Reflectarray Antenna. John Wiley and Sons, Inc, Publication, 2007.

[10] M. H. Jamaluddin, R. Gillard, R. Sauleau, L. Le Coq, X. Castel, R. Benzerga, and T. Koleck, "A dielectric resonator antenna (DRA) reflectarray," Eur. Microw. Week 2009, EuMW 2009 Sci. Prog. Qual. Radiofreq. Conf. Proc. - 39th Eur. Microw. Conf. EuMC 2009, vol. 6164, no. October, pp. 25-28, 2009.

[11] M. H. Jamaluddin, G. C. Eu, S. K. Abdul Rahim, and N. I. Dzulkipli, "Wideband Aperture-Coupled Dielectric Resonator Antenna at 5.8 GHz,” J. Teknol. (Sciences Eng., vol. 69, no. 1, pp. 25-30, 2014.

[12] K.-M. Luk and K.-W. Leung, Dielectric Resonator Antennas, no. c. England: Research Studies Press, 2003.

[13] Z. Rahimian, "Circularly Polarized Cylindrical Dielectric Resonator Antenna with Different Shapes Cross Slot," vol. 4, no. 6, pp. 974-978, 2014.

[14] E. Lim, H. Y. Wong, and F. L. Lo, "Rectangular DRA Reflectarray with an Inclined Top-loading Micostrip Patch," pp. 878-881, 2014.

[15] R. Florencio, J. Encinar, R. R. Boix, and G. Perez-palomino, "Dual-polarisation reflectarray made of cells with two orthogonal sets of parallel dipoles for bandwidth and cross-polarisation improvement," IET Microwaves, Antennas Propag., vol. 8, no. 15, pp. 1389-1397, 2014.

[16] F. Ahmadi, K. Forooraghi, Z. Atlasbaf, and B. Virdee, "Dual linear-polarized dielectric resonator reflectarray antenna," IEEE Antennas Wirel. Propag. Lett., vol. 12, pp. 635-638, 2013.

[17] A. Petosa, Dielectric resonator antenna handbook. Artech House Publishers, 2007.

[18] Final Acts WRC, "In World Radiocommunication Conference Geneva: International Telecommunication Union," World Radiocommun. Conf., vol. 238, pp. 25-27, 2015.

[19] J. Shaker, M. R. Chaharmir, and J. Ethier, Reflectarray Antennas: Analysis, design, fabrication, and measurement. Artech House Publishers, 2013.

[20] M. Y. Ismail and M. Inam, "Resonant Elements for Tunable Reflectarray Antenna Design," Int. J. Antennas Propag., vol. 2012, pp. 1-6, 2012.

[21] R. K. Mongia and A. Ittipiboon, "Theoretical and experimental investigations on rectangular dielectric resonator antennas," IEEE Trans. Antennas Propag., vol. 45, no. 9, pp. 1348-1356, 1997.

[22] A. Kiyani and M. Y. Ismail, "Design and analysis of high performance reflectarray resonant elements," Procedia Eng., vol. 53, pp. 248-254, 2013.

\section{BIOGRAPHIES OF AUTHORS}
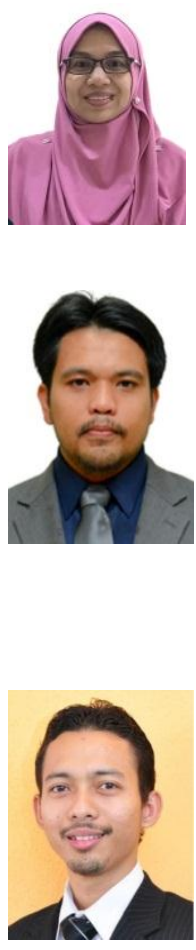

Nur Fazreen Sallehuddin received her Bachelor degree in Electrical Engineering (Hons.) (2006) and Master degree in Technic and Vocational Education (2014) from Universiti Tun Hussein Onn Malaysia (UTHM). Experienced as Integration Assistant Engineer and Quality Assurance Engineer for solar industry and automotive industry respectively from 2007-2011. Currently she is pursuing the Ph.D. degree in Electrical Engineering at Wireless Communication Centre, University Technology of Malaysia (UTM). Her research interests and areas include dielectric resonators and reflectarray antennas design in 5G applications and millimeter waves.

Mohd Haizal Jamaluddin received the bachelor's and master's degrees in electrical engineering from Universiti Teknologi Malaysia, Malaysia, in 2003 and 2006, respectively, and the Ph.D. degree in signal processing and telecommunications from the Université de Rennes 1, France, in 2009, with a focus on microwavecommunication systems and specific antennas such as dielectric resonator and reflect array and dielectric dome antennas. He joined the Department of Electronic Engineering, Faculty of Electrical Engineering, Universiti Teknologi Malaysia, as a Tutor in 2003. He is currently an Associate Professor with the Wireless Communication Centre, Universiti Teknologi Malaysia (UTM). He was a Senior Lecturer at Wireless Communication Centre (WCC), Universiti Teknologi Malaysia (UTM) until December 2017. He has published more than 40 ISI/Scopus papers in reputed indexed journals and more than 40 conference proceedings.

Muhammad Ramlee Kamarudin (Senior Member IEEE 13', Member IEEE 08', Member IET 11') obtained his first degree from Universiti Teknologi Malaysia (UTM), Johor Bahru, Malaysia, with honours, majoring in electrical and telecommunication engineering and graduated in 2003 . He received the M.S. degree in communication engineering in 2004 from the University of Birmingham, Birmingham, UK, and later he obtained his Ph.D. degree in 2007 from the same University under the supervision of Professor Peter Hall. Dr Kamarudin is currently working as a Senior Lecturer at the Centre for Electronic Warfare, Information and Cyber (EWIC), Cranfield Defence and Security, Cranfield University, UK. Prior to this appointment, he was an Associate Professor at Wireless Communication Centre (WCC), Universiti Teknologi Malaysia (UTM), Malaysia until May 2017. He holds a H-Index of 19 (SCOPUS) and more than 1350 citations (SCOPUS). He is an author of a book chapter of a book entitled Antennas and Propagation for Body-Centric Wireless Communications and has published more than 200 technical papers in journals and proceedings 
including IEEE Transaction on Antenna and Propagation (TAP), IEEE Antennas and Wireless Propagation Letter (AWPL), IEEE Antenna Magazine, IEEE Access, International Journal of Antennas and Propagation (IJAP), Progress in Electromagnetics Research (PIER), Microwave and Optical Technology Letters (MOTL), and Electronics Letters. His research interests include antenna design for 5G, wireless on-body communications, in-body communications (implantable antenna), $\mathrm{RF}$ and microwave communication systems, and antenna diversity. Dr Kamarudin is an IEEE Senior Member (SMIEEE), a Member of IET (MIET), an Executive Member of Antenna and Propagation (AP/MTT/EMC), Malaysia Chapter, and a Member of IEEE Antennas and Propagation Society, IEEE Communication Society, IEEE Microwave Theory and Techniques Society and IEEE Electromagnetic Compatibility Society.
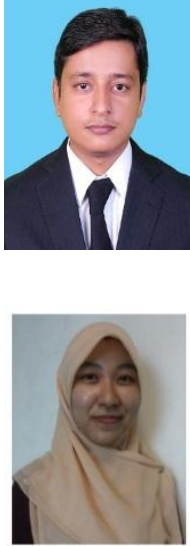

Muhammad Hashim Dahri received the B.E degree in Telecommunications from the Mehran University of Engineering and Technology (MUET), Pakistan, in 2010 and the Masters by Research degree in Electrical Engineering from Universiti Tun Hussein Onn Malaysia (UTHM) in 2014. He is currently pursuing the Ph.D. degree with the Wireless Communication Centre (WCC), Universiti Teknologi Malaysia (UTM). He has authored over 20 research papers in various indexed journals and conference proceedings. His research interests include reflectarray antennas, planar printed antennas and tunable materials for antenna design.

Siti Umairah Tajol Anuar received her Bachelor degree in Electronic Telecomunication Engineering (2015) in Universiti Malaysia Sarawak (UNIMAS) and Master in Electronic Telecommunication (2017) from Universiti Teknologi Malaysia (UTM). She is currently pursuing her Ph.D. at the Universiti Teknologi Malaysia (UTM). Her research interests and areas include dielectric resonators antennas and wireless communication. 